\title{
ESTIMATION OF STATURE FROM LENGTH AND BREADTH OF LEFT THUMB IN MEDICAL STUDENTS OF A MEDICAL COLLEGE IN KATHMANDU, NEPAL
}

\author{
Barshika Katwal, Nirajan Shrestha and Bhumikala Limbu
}

Department of Forensic Medicine, Nepal Medical College Teaching Hospital, Attarkhel, Gokarneshwor-8,

\begin{abstract}
There is enormous importance of identification for forensic experts. Identification of human remains is always challenging for them, worldwide. An individual's parameter has been an intrinsic representative among the other parameters. To specify the relationship between height and finger length in healthy persons, both male and female, an effort has been made to originate the regression formula. A descriptive and cross-sectional study was conducted at Department of Forensic Medicine, Nepal Medical College Teaching Hospital, Kathmandu with sample size 100 males and 100 females of 18-25 years of age. The stature of male subjects was $170.02 \mathrm{~cm}$ mean value with SD $( \pm 6.40)$. The minimum stature observed was $152.5 \mathrm{~cm}$ while maximum was 188 $\mathrm{cm}$. In males, mean of the left thumb length was $3.2 \mathrm{~cm}$ with SD $( \pm 0.38)$. Also, breadth of the left thumb showed a mean value of $2.52 \mathrm{~cm} \mathrm{SD}( \pm 0.46)$ with Pearson coefficient $(0.258)$. By means of linear regression analysis a constant (147.096) and Pearson correlation coefficient (0.337) were obtained for the length of left thumb. In female subjects, stature was found to be $157.76 \mathrm{~cm}$ mean value with SD $( \pm 6.30)$. The minimum stature was $136.00 \mathrm{~cm}$ and maximum was $175.00 \mathrm{~cm}$. The mean of left thumb length was $2.95 \mathrm{~cm}$ and $2.25 \mathrm{~cm}$ for breadth with SD $( \pm 0.4166)$ for both. Applying multiple regression, a constant (148.83) and Pearson coefficient $(0.25)$ were obtained for left thumb length and SD $( \pm 0.423)$ was obtained for left thumb breadth. In males the stature can be estimated using standard equation ( $\mathrm{S}=150.49+4.65 \mathrm{LTL}+1.82 \mathrm{LTB})$. In females, stature can be estimated using standard equation $(S=148.83+4.4114 \mathrm{LTL}+1.423 \mathrm{LTB})$, where $\mathrm{S}=$ stature, $\mathrm{LTL}=$ left thumb length, LTB= left thumb breadth. A multiple regression equation derived by our study can be used for estimation of height in Nepalese population. If either of the measurements (left thumb length and breadth) is known, the other can be calculated. It is remarked that length and breadth of left thumb shows positive relationship with the stature.
\end{abstract}

\section{KEYWORDS}

Bone length, identification, left thumb length/breadth, linear regression, stature

Received on: December 10, 2020

Accepted for publication: March 21, 2021

\section{CORRESPONDING AUTHOR}

Dr. Barsika Katwal,

Department of Forensic Medicine,

Nepal Medical College Teaching Hospital,

Attarkhel, Gokarneshwor-8, Kathmandu, Nepal.

Email: barshika@hotmail.com

Orcid No: https://orcid.org/0000-0002-9429-7639

DOI: https://doi.org/10.3126/nmcj.v23i2.38511 


\section{INTRODUCTION}

There is an enormous importance of identification for forensic experts. Identification of human remains is always challenging for them, worldwide. An individual's parameter has been an intrinsic representative among the other parameters. By the length of few long bones and appendages of the body, their proportion to the total stature can be obtained. To specify the relationship between the height and finger length in healthy persons of both male and female an effort has been made to generate the regression formula. ${ }^{1}$

This study is considered as an area of interest in fields of forensic medicine, physical anthropologist and human biologist. For forensic scientists, it is also helpful to conclude the stature from remains of upper limb., ${ }^{2,3}$ Some of them have tried using the length of hand, foot and arm span etc. ${ }^{4,5}$ for estimation of stature from human remains. An effort is made in the current study to find the correlation between stature and hand length in humans of age 1825 years.

Anthropometry is normally regarded as an established and conceivably the essential apparatus of biological anthropology. It also has an extensive application in forensic sciences, and it is receiving amplified use in medical sciences, especially in the discipline of Forensic Medicine and Anatomy. The decisive endeavor of use of anthropometry in medical science is to ease the law enforcement agencies in achieving individual's identity in case of unidentified human remains. ${ }^{6}$ Stature provides vision into various features of a population including nutrition, health and genetics; geographical location, environment and climatic condition. The stature of an individual is an essential characteristic; its estimate is considered to be an important assessment in the identification of unknown human remains. Adult height may be attained anywhere from the early teens to early twenties, though it is most commonly reached during mid-teens for females and the late-teens for males. ${ }^{7}$ When intact bodies are to be examined, stature estimation does not pose any problem. Most methods employ the basic process of comparison. ${ }^{8}$ A number of workers have studied the correlation between stature and various long and short bones of the body. Many of them have correlated the dimensions of hand with the stature. But very few studies of stature estimation are reported based on digits and phalanges of hand. Thus, the present study is planned to find out a relationship of length of hand and phalanges with body stature in Nepal.

\section{MATERIALS AND METHODS}

A descriptive and cross-sectional study was conducted at the Department of Forensic Medicine, Nepal Medical College Teaching Hospital (NMCTH), Kathmandu. In this study, sample size of 100 males and 100 females of 18-25 years of age was taken among volunteer MBBS students, non-consenting students and those with any kind of deformities in hand like amputation of fingers, metabolic disorders and congenitally malformed limbs were excluded. Ethical approval was obtained from the Institutional Review Committee (IRC) of NMCTH. Data was analyzed by using Statistical Package for Social Sciences (SPSS) version 17. Data was expressed in mean, coefficient value (r), p-value, multiple regression and standard deviation.

Materials required: A digital Vernier Calliper was used to measure the accurate length of the left thumb as showed in figure and Stadiometer was used to measure the height of the student with bare foot.

Stature: The student was asked to stand barefooted with feet slightly separated on the base of stadiometer. Heels, buttocks, and back were brought in contact with the vertical surface. The head of the students was positioned in Frankfurt plane with bi-auricular plane being horizontal. The headpiece of stadiometer was kept firmly over the vertex to compress the hair and height was measured. ${ }^{9}$ The same method was applied to every volunteer.

Finger length: The breadth of left thumb is the linear interphalangeal distance between the lateral and medial side of the left thumb. The length of left thumb is the distance between the proximal flexion creases of the finger to the tip of the respective finger. ${ }^{10}$

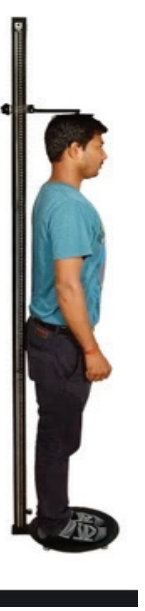

Fig. 1: Stadiometer to measure height 


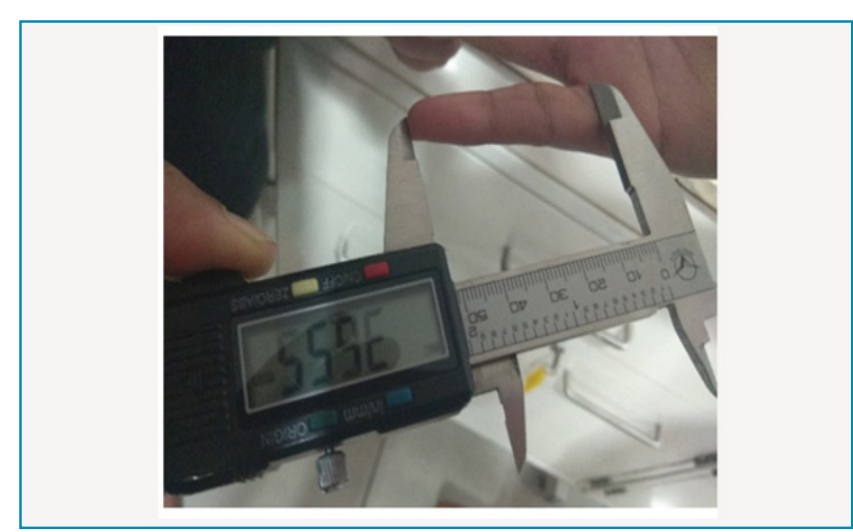

Fig. 2: Digital Vernier Calliper to measure length of finger

\begin{tabular}{|l|l|l|}
\hline \multicolumn{2}{|c|}{ Regression analysis for prediction of stature } \\
\hline $\begin{array}{l}\text { Multiple linear } \\
\text { regression } \\
\text { formula }\end{array}$ & $\begin{array}{l}\text { Total subjects } \\
(\mathrm{n}=200)\end{array}$ & $\begin{array}{l}\text { Standard } \\
\text { Error } \\
\text { Estimate } \\
\text { (SEE) }\end{array}$ \\
\hline $\mathrm{Y}=\mathrm{a}+\mathrm{bX}$ & $\begin{array}{l}\mathrm{S}=150.49+4.65 \\
\text { length +1.82 } \\
\text { breath (male) }\end{array}$ & 6.04 \\
\hline $\mathrm{Y}=\mathrm{a}+\mathrm{bX}$ & $\begin{array}{l}\text { S=148,83+4.114 } \\
\text { length +1.423 } \\
\text { breath (female) }\end{array}$ & 6.15 \\
\hline
\end{tabular}

Where, Y: Height, a: Intercept constant, b: Regression coefficient, $\mathrm{X}$ : Average length, breadth of left thumb

\section{RESULTS}

Descriptive statistics for stature, left thumb measurements and its correlation in male and female are presented in Table 1 . The stature of male subjects was $170.02 \mathrm{~cm}$ mean value with SD $( \pm 6.40)$. The minimum stature observed was $152.5 \mathrm{~cm}$ while maximum was $188.0 \mathrm{~cm}$. In males, mean of the left thumb length was 3.2 $\mathrm{cm}$ with SD $( \pm 0.38)$. Breadth of the left thumb showed a mean value of $2.52 \mathrm{~cm} \mathrm{SD}( \pm 0.46)$ with Pearson correlation coefficient (0.258). By means of multiple regression analysis a constant (147.096) and Pearson correlation coefficient (0.337) was obtained for the length and breadth of left thumb. There was statistically significant correlation between stature, left thumb length and breadth measurements $(\mathrm{p}<0.001)$.

In female subjects, stature was found to be $157.76 \mathrm{~cm}$ mean value with SD $( \pm 6.30)$. The minimum stature was $136.00 \mathrm{~cm}$ and maximum was $175.00 \mathrm{~cm}$. The mean of left thumb length was $2.95 \mathrm{~cm}$ and $2.25 \mathrm{~cm}$ for breadth with SD $( \pm 0.4166)$ for both. Applying multiple regression, a constant (148.83) and Pearson coefficient $(0.25)$ were obtained for left thumb length and SD $( \pm 0.423)$ was obtained for left thumb breadth in case of female candidates. By seeing the results statistically, significant correlation existed in-between stature, left thumb length and breadth measurements $(\mathrm{p}<0.001)$.

Statistical significance $(p<0.001)$ between left thumb length and breadth with stature, is shown in Table 2. The regression equation can be formulated by using the values obtained from multiple regression analysis. In males the stature can be estimated using standard equation $(\mathrm{S}=150.49+4.65 \mathrm{LTL}+1.82 \mathrm{LTB})$. In females, stature can be estimated using standard equation $(S=148.83+4.4114 \mathrm{LTL}+$ 1.423LTB) where $S=$ stature, $\mathrm{LTL}=$ left thumb length, LTB= left thumb breadth.

To estimate stature from (length and breadth of left thumb) right- and left-hand dimensions of male and female, the multiple regression equations with the value of the standard error of estimation (SEE), the coefficient of correlation (r), the coefficient of determination and $\mathrm{R}^{2}$ values are shown in Table 2 . The regression coefficients are statistically significant ( $p<$ 0.001) for all the derived equations of left thumb parameters of males and females. The

\section{Table 1: Comparative statistics of stature, left thumb length and left thumb breadth}

\begin{tabular}{|llccccccc|} 
Sex & Variable & Min & Max & Mean & SD & Constant & r & P-value \\
$\begin{array}{l}\text { Male } \\
(100)\end{array}$ & Stature (cm) & 152.5 & 188.0 & 170.02 & 6.40 & 150.493 & 0.352 & .000 \\
& Finger (LTL) & 2.2 & 3.90 & 3.20 & 0.38153 & 147.096 & 0.337 & .000 \\
& Finger (LTB) & 1.5 & 3.8 & 2.5273 & 0.46419 & 161.047 & 0.258 & .000 \\
Female & Stature (cm) & 136.0 & 175.0 & 157.76 & 6.30 & 148.831 & 0.243 & .000 \\
$(100)$ & Finger (LTL) & 2.0 & 5.08 & 2.95 & 0.41662 & 147.096 & 0.257 & .000 \\
& Finger (LTB) & 1.1 & 3.60 & 2.2599 & 0.41662 & 157.61 & 0.423 & .000 \\
\hline
\end{tabular}


Table 2: Multiple regression of stature

\begin{tabular}{|c|c|c|c|c|c|}
\hline Gender & Side & Equation & $\begin{array}{c}\text { SEE (Standard Error of } \\
\text { Estimate) }(\mathrm{cm})\end{array}$ & $\mathbf{R}$ & $\mathbf{R}^{2}$ \\
\hline Male & Left & $\begin{array}{c}S=150.49+4.65 \\
\text { length }+1.82 \text { breadth }\end{array}$ & 6.04 & 0.357 & 0.128 \\
\hline Female & Left & $\begin{array}{c}\mathrm{S}=148.83+4.114 \text { length }+1.423 \mathrm{br} \\
\text { eadth }\end{array}$ & 6.15 & 0.257 & 0.066 \\
\hline
\end{tabular}

coefficient of correlation between stature and hand measurements varies from +0.285 to +0.545 in males and from +0.411 to +0.644 in females. The larger value of $\mathrm{R}$ is found between stature and female left-thumb length and the lower value of $\mathrm{R}$ is found between stature and male left-thumb breadth. The value of the coefficient of determination $\left(\mathrm{R}^{2}\right)$ varies between +0.081 and +0.297 in males and between +0.169 and +0.414 in females. The correlation ranged from weak to moderate value for both male and female. The standard error of estimation for males varies from \pm 5.347 to $\pm 6.112 \mathrm{~cm}$ and for females varies from \pm 3.688 to $\pm 4.393 \mathrm{~cm}$. The larger value of the standard error of estimation is found for male left-thumb breadth and the lower value is found in female left thumb length. Though, our result shows few variations in stature that can be predicted by left thumb dimension, it is a strong equation to correlate during disaster, when thumb is the only way to identify a person.

\section{DISCUSSION}

Scientists have underlined the need for population-specific stature estimation formulae as the ratios of various body parts to stature differ from one population to another. A number of studies done earlier have utilized the upper extremity such as humeral length, arm length, arm span, hand length, hand breadth and metacarpal length measurements to predict human stature. ${ }^{11-16}$ This study aims at determining stature from left thumb measurements and formulating a multiple regression equation for estimation of stature from left thumb dimensions. In this study 200 Nepalese subjects of age group 18-25 years were studied and it was established that there was significant positive $\mathrm{p}$-value $(\mathrm{P}<0.001)$ between stature and left thumb dimensions in males and females. Pearson correlation between left thumb length and stature was higher among males as compared to females. Our finding is in accordance with a study conducted in India by Rastogi in 2009. ${ }^{9}$ On prediction of stature from middle finger length in Indian population where Pearson correlation between middle finger length and stature was higher among males in a study conducted by Suseelamma in $2014 .{ }^{17}$ In correlation between stature and length of fingers Pearson correlation between finger length and stature was higher among males than females. Previous studies have been conducted to estimate statures using fingers and phalanges in adults of various ethnicities ${ }^{18,19}$ Trotter and Glesser ${ }^{20}$ have confirmed requirement of different regression equations among different races after studying different races for relationship between lengths of long bones and stature. ${ }^{10}$ Data taken from Indian population confirmed that there is a positive correlation between the middle finger length and the stature. ${ }^{21}$ In Korean population also it was observed a positive correlation between each finger and the stature. The middle finger of males and the ring finger for females were the most correlated with stature. The study in Korea showed the correlation between the length of phalanges and the stature is more significant in the adolescent populations of Koreans than in adults confirming finger length and stature of various ethnicities in adolescence were different. $^{21-24}$ In addition to ethnic differences; material trends used by person can also influence body proportions. One study has also emphasized the need to identify the age group, race and area that a particular person belongs to, before applying the regression equation and to that age group to identify the stature of the individuals. $^{25-27}$

Relating, the regression models derived for stature estimation in this study, it was observed that the accuracy of predicted stature estimation in both regression models was estimated higher for males than for females. In Nepalese male adolescents, the coefficient of determination of the regression equation using the left thumb measurements was higher than that of adults in Egypt, India, Iran, and Korea and adolescents in India. ${ }^{24-28}$ In Nepalese female adolescents, the coefficient of determination of the regression equation using left thumb measurements was higher than that of adults in Egypt and Korea but lower than that of India and Iran. ${ }^{28}$ 
After taking the measurements from both the males and females it can be concluded that males have larger finger length and height. By the above given criteria the calculations were done. It can be understood from this study that with the help of the multiple regression equation the successful estimation of stature can be done conveniently. ${ }^{29,30}$

Evaluation of stature of a discrete part of fragmented remains is still a very demanding work despite numbers of studies carried out, as formula derived in a certain population does not fit worldwide because of genetic, ethnic, dietary, climatic and other innumerable differences. Multiple regression equation derived by our study can be used for estimation of height in Nepalese population. If either of the measurements (left thumb length and breadth) is known, the other can be calculated. It is remarked that length and breadth of left thumb shows a multiple relationship with the stature, from which stature is normally studied. However, it is required to transform the measurements on stature to obtain proper regression equations. Furthermore, due to dissimilarities in finger measurements among people of different regions and races of Nepalese medical students and hence that stature estimation becomes more precise to identity an individual easily.

\section{ACKNOWLEDGMENTS}

The authors are grateful to all NMC students who participated voluntarily and cooperated for the success of this study. We would like to thank Assoc. Prof. Dr. Siddharth Timilsina of Department of Forensic Medicine, Manipal Medical College, Pokhara and Asst. Prof. Mr. Rajan Pandit of Department of Physiology, NMC, who helped me to complete this study.

Source of Research Fund: None

Conflict of Interest: None

\section{REFERENCES}

1. Wilbur AK. The utility of hand and foot bones for the determination of sex and the estimation of stature in a prehistoric population from west central Illinois. Int'l J Osteoarchaeol 1998; 8:18091.

2. Nat BS. Estimation of stature from long bones in Indians of the United Province: A medicolegal inquiry in anthropometry. Indian J Med Res 1931; 1245-63.

3. Dupertuis CW, Hadden JA. On the reconstruction of stature from long bones. Amer $J$ Physiol Anthropol 1951; 15-53.

4. Saxena HK. The estimation of stature from head length. J Anat Soc India 1979; 28: 53.

5. Pawar PK, Dadhich A. Study of correlation between height and hand length in residents of Mumbai. Int'l J Biol Med Res 2012; 2071-75.

6. Işcan YM. Global forensic anthropology in the 21st century. Forensic Sci Int'l 2001; 117: 1-6.

7. Ghai OP, Jain V, Sankhayan N, Agarwal R. Normal growth and its disorder. In: Ghai OP, Paul VK, Bagga A, editors. Essential Pediatrics. 7th ed. New Delhi: CBS Publishers and Distributors Pvt Ltd.; 2009: 5.

8. Suseelamma D, Gayathri P, Deepthi S et al. Study of correlation between stature and length of fingers. Sch J App Med Sci 2014; 773-84.

9. Rastogi P, Kanchan T, Menezes RG, Yoganarasimha K. Middle finger length - a predictor of stature in the Indian population. Med Sci Law 2009; 49: 123-6.
10. Rastogi P, Nagesh KR. Estimation of stature from hand dimensions of north and South Indians. Leg Med (Tokyo) 2008; 10:185-9.

11. Saxena A. Bayesian Estimation of T-G Ridge Model. Statistica Neerlandica1984; 38: 257-60.

12. Kulkarni AL, Patki PS. Indian Anthropologist. Indian Anthropol Assoc 1989; 48: 13-21.

13. Bennett M, Budka M. Digital technology for forensic footwear analysis and vertebrate ichnology.

14. Radoinova DD, Tenekedjiev K, Yordanov $\mathrm{Y}$. Stature estimation from long bone lengths in Bulgarians. J Comparative Human Biol 2002; 52: 221-32.

15. Singh A, Kumar A, Chavali KH, Harish D. Use of arm-span and foot length for estimation of height of the person. Punjab Acad Forensic Med Toxicol 2012; 12: 87-91.

16. Kanchan T, Krishan K, Geriani D et al. Estimation of stature from the width of static footprintsInsight into an Indian model. Elsevier Forensic Sci Int'l 2013; 23: 136-9.

17. Suseelamma D, Gayathri P, Deepthi S et al. Study of correlation between stature and length of fingers. Sch J App Med Sci 2014; 2: 773-84.

18. Patel MP, JoshiI NB, Dongre AV. Regression equation of height on tibial length. Indian J Med Res 1964; 52: 531-4.

19. Mahakizadeh S, Moghani-Ghoroghi F, Moshkdanian Gh, Mokhtari T, Hassanzadeh G. The determination of correlation between stature and 
upper limb and hand measurements in Iranian adults. Forensic Sci Int'l 2016; 260: 27-30.

20. Trotter M, Gleser GC. Estimation of stature from long bones of American Whites and Negroes. Amer J Phys Anthropol 1952; 10: 463-514.

21. Jee S-C, Yun MH. Estimation of stature from diversified hand anthropometric dimensions from Korean population. J Forensic Legal Med 2015; 35: 9-14.

22. Ilsun R, Wonjoon K. Estimation of stature from finger and phalange lengths in a Korean adolescent. J Physiol Anthropol 2019; 38: 13.

23. Zeybek G, Ergur I, Demiroglu Z. Stature and gender estimation using foot measurements. Forensic Sci Int'l 2008; 181: 54.

24. Kim W. A comparative study on the statistical modelling for the estimation of stature in Korean adults using hand measurements. Anthropol Anz 2019; 76: 57-67.

25. Yadav SK, Mandal BK, Karn A. Determination of stature from ulnar length in Nepalese population. Eur J Forensic Sci 2015; 2: 5-8.
26. Agnihotri AK, Agnihotri S, Jeebun N, Googoolye K. Prediction of stature using hand dimension. $J$ Forensic Leg Med 2008; 15: 479-82.

27. Pearson K. Pearson mathematical contributions to the theory of evolution. On the reconstruction of the stature of prehistoric races. Philosophical Transection of Royal Society; London; 1899; 192: 169-224.

28. Sahar RH, Nashwa NK. Stature estimation from hand and phalanges lengths of Egyptians. J Forensic Leg Med 2010; 17: 156-60.

29. Maloy MK, Tapan JK, Jonaki D et al. Use of length of ulna for estimation of stature in living adult male in Burdwan district and adjacent areas of West Bengal. J Anat Soc India 2009; 58:16-8.

30. Sarojini HD, Das BK, Purnabati S et al. Estimation of stature from upper arm length among the Marings of Manipur. Indian Med J 2006; 100: 2713. 